\title{
Coping Strategies of Newly Graduated Nurses (NGNs) in the First Year of Clinical Practice: A Grounded Theory Study
}

\author{
Mahbobeh Sajadi, ${ }^{1}$ Forough Rafii, ${ }^{2,}$ Vahid NaseriSalahshour, ${ }^{3}$ and Naeimeh Seyedfatemi ${ }^{2}$ \\ ${ }^{1}$ School of Nursing and Midwifery, Arak University of Medical Sciences, Arak, IR Iran \\ ${ }^{2}$ School of Nursing and Midwifery, Iran University of Medical Sciences, Tehran, IR Iran \\ ${ }^{3}$ Student Research Committee, Arak University of Medical Sciences, Arak, IR Iran \\ "Corresponding author: Forough Rafii, Ph.D. of Nursing Education, School of Nursing and Midwifery, Iran University of Medical Sciences, Tehran, IR Iran. Tel: +98-2188201880, \\ E-mail: fnm@iums.ac.ir
}

Received 2018 August 10; Revised 2018 February 21; Accepted 2018 March 06.

\begin{abstract}
Background: The first year of clinical work is one of the most important steps in the career life of nurses. Although some studies have been done regarding NGNs, a few studies have been conducted about coping strategies of newly graduated nurses in the first year of clinical work. The aim of this study was to explore and describe the coping strategies of NGNs in the first year of clinical work in Tehran, the capital of Iran.

Methods: This study was conducted using the grounded theory methodology. In this study, 20 participants were selected using a purposive and theoretical sampling method. The data were collected by semi-structured in-depth interviews. For data analysis, the constant comparison method based on Strauss - Corbin approach was used.

Results: Data analysis revealed that two strategies were used by NGNs, which included "positioning" at the beginning of work and then later, stabilizing the obtained "position (place)". The core category of this study was "struggles to settle in the workplace."

Conclusions: This study showed that NGNs tried to create a perfect position in the ward and then consolidate the created position. The results of this study can serve as a good guide to develop training and supporting programs for NGNs and be used in helping them adapt better to the new position. However, it is recommended to do further studies in this regard.
\end{abstract}

Keywords: Newly Graduated Nurse, Coping Strategies, Clinical Practice, Grounded Theory Study, Nurse

\section{Background}

Starting clinical practice (work) is a challenging phenomenon (1). The majority of nursing graduates faces with the reality shock and experience a significant psychological stress $(1,2)$. Research has shown that NGN, following the start of work, would realize that they are not ready enough and there are contradictions between the knowledge and skills acquired during education and the behaviors expected of them at work. Therefore, some NGNs are not able to handle such conflicts and leave the profession (3-5).

In fact, the reality shock is a threatening situation for NGNs and can be one of the major stressful factors at the beginning of their new role (6). In this regard, a study has shown that nursing graduates have not succeeded to meet the expectations of the organization effectively (5). In addition, the NGNs are expected to be qualified nurses and do their work very accurately and perhaps, they are expected to act as highly experienced nurses. Due to conflicts between expectations and realities of the workplace, these issues will cause the newly graduated nurses fail to adapt themselves appropriately to the conditions. As a result, they represent physical and mental distresses and develop complications such as anxiety, fatigue, increased illness, and job dissatisfaction (7).

NGNs have to experience a stressful and difficult transition period to acquire required abilities at the nursing profession (8). Several studies have pointed out the gap between the carrier expectations of NGNs and their actual performance that in addition to imposing high costs upon the organization, can lead to feelings of loss, failure, incompetence, insecurity, and helplessness in the rookie nurses and provide the ground for their job dissatisfaction and turnover $(8,9)$. Graduation is a major life event that transition through it would affect all aspects of the student' life. Beginning work in the health profession, particularly for nurses, is associated with more stress than other professions (5). In this regard, Hezaveh et al. (4) suggest that probably newly graduated nurses lack the required preparedness for dealing with the working complex conditions (10). Currently, Iran, like many countries, is ex- 
periencing a shortage of nurses and facing the increased workload of nurses. In addition, as training clinical nurses in Iran needs a 4-year course, therefore, the policymakers on health professions need to try effectively to retain and maintain the graduated nurses in the profession (1).

Understanding the NGNs' coping strategies to deal with these issues appears to be very important; it can be used as a guide for nursing managers, officials of hospitals, nursing educators, and teachers and it can increase the nursing knowledge in this regard. A few studies have been conducted on NGNs strategies; however, the results of other studies showed that NGNs at the start of their work have experiences such as lack of adequate preparation, stress, suffering, and lack of support. Thus, this study was designed to further understand the coping strategies used by NGNs in the first year of clinical work. Since these coping strategies cannot be thoroughly evaluated with traditional research techniques, this study was conducted using a qualitative method. It was considered that NGNs strategies were in interaction with other nurses and in the context of the social environment (11). Due to its unique characteristics, grounded theory is an appropriate method to explore the coping strategies of NGNs in the first year of clinical work. Therefore, this study aimed to explore the coping strategies used by newly graduated nurses in the first year of clinical work.

\section{Methods}

\subsection{Data Collection}

This study was performed using grounded theory approach, after obtaining the ethics license from Iran University of Medical Sciences, consent form of the participating in the study and confidentiality of information of the participants. The study was performed in 2011-2012 at four teaching hospitals (Shahid Motahhari, Hazrat-erasoul, Shahid Rajaei, and Firoozgar) affiliated to Iran University of Medical Sciences in Tehran. In this study, 17 NGNs were selected using the purposeful and theoretical sampling method. The NGNs were spending their first year of work in the teaching hospitals. The sampling was done from different hospitals, wards, shifts and with different work experiences.

According to the theoretical sampling, 3 head-nurses were also interviewed. The sampling was continued to reach the theoretical saturation (12).

The data were obtained by using semi-structured indepth interviews. The participants' described experiences were recorded during the interviews. At the end of each interview, the recorded findings were transcribed and analyzed. Then, the next interview was made. The interview elementary questions were as such to encourage the participants to speak freely about their experiences. For example, at the beginning of the interview, the newly graduated nurses were asked to explain their experiences in the early days of starting work. Then, based on the data obtained, questions were raised more specifically about their coping strategies in the face of concerns and problems. The data collection was continued until data saturation was accomplished $(12,13)$.

\subsection{Research Design}

At the end of each interview and using Strauss-Corbin analysis method (1998) and through applying constant comparison in the development of concepts, the relevant categories and properties were coded. By constant comparison of each data set with other data sets in the development of concepts, the categories and subcategories were compared.

Accordingly, three phases of open coding, axial coding, and selective coding were followed. In open coding, the data were initially read word by word and line by line; their main concepts were extracted and identified as codes. Gradually, by comparing their characteristics and dimensions, the concepts were classified. In the axial coding, the obtained categories were related to each other using the paradigmatic coding, i.e., concentrating on the conditions, coping strategies, and outcomes. Finally, using the selective coding, the original story of the study was discovered. At this stage, the core category was determined (12-14). In order to increase the credibility, in addition to using the constant comparative analysis, the prolonged engagement and spending enough time to collect and analyze the data, the use of integration method in information resources, multiple methods to collect data such as interviews, and field notes were used. Moreover, the memo writing, review by the participants, data analysis by supervisors, advisers, and peer review were applied (15). In addition, for transferability, using background and characteristics descriptions of the participants and describing the study context, the researcher provided conditions to use the findings in other contexts (15).

The reliability was evaluated by step-by-step auditing (14). In this study, the data and documents were carefully examined by instructors, advisors, and reviewers. To achieve conformability, all stages of research, in particular, the data analysis processes, were recorded in details.

In addition, a number of interviews, codes, and derived categories were provided to the researcher's colleagues and number of faculty members familiar with the analysis of qualitative research, and they were asked to examine the accuracy of the coding process. 


\section{Results}

The demographic characteristics of participants in this study are presented in Table 1 . By using grounded theory, the study revealed the coping strategies employed by Iranian NGNs in the clinical practice.

Data analysis and interpretation revealed that the NGNs tried to create a place for themselves in the clinical workplace and then gradually consolidate their position. The main categories and their subcategories are shown in Table 2.

\subsection{Positioning}

\subsubsection{Learning}

Analysis of interviews with participants in the study showed that in the early stages of beginning the work, a strategy used by fresh graduates was to create a place for themselves.

This strategy was extracted from a invivo code of one of the participants. This strategy was used during the first 4 months of the work. To make this work, they benefited from solutions including "learning" and "subordination and obedience." About learning, one of the NGNs (participant No. 4) said:

"I'm always trying to learn everything; I go with my colleagues to learn dressings, administrating the medicines, preparing sets, etc., overall, the ward's routine. I watch how our head nurse deals with the patients; how s/he answers them; in this way, I learn from him/her."

Learning was done through various methods such as study, discussions with friends, gaining experience, and choosing a role model. One of the nurses (participant No. 5) mentioned choosing the head nurse as a role model and said:

"Our head nurse is a highly educated nurse; s/he knows everything... I try to learn from him/her and master on everything like him/her."

A head nurse (participant No. 19) said:

"In the first month, they are always learning. So, we put them with more experienced colleagues in the mornings to learn things and gain the necessary skills."

\subsubsection{Subordination and Obedience}

Sometimes the beginners, to create a place for them, tried to follow the subordination and obedience to their chief nurse so that they did not even complain about their busy schedule and endured all the problems. In this regard, a participant (nurse No. 9) said:

"Whatever our head nurse says, I obey and do." In addition, another nurse (nurse No. 7) stated:

"Here ... if you object, they will change you to another ward. You need to coordinate with their routine. So, ...I do not object. Even when there is a problem in the workplace, I come to work to gain their trust. That's why I have almost got a place for myself here."

\subsection{Position Consolidation}

After a while, the newly graduated tried somehow to consolidate their position. For this purpose, they used the strategy of solidifying the position. This strategy began almost from about the fifth month of work at the bedside. At this point, a newly graduated nurse had somewhat earned capabilities to be able to accept the responsibilities in the workplace. At this stage, he had acquired so much competence to prioritize the tasks and do them at the right time. The strategy including two sub-categories of "aligning themselves with colleagues" and "showing their capabilities" was used accordingly.

\subsubsection{Aligning Oneself with Colleagues}

Some newly graduated nurses at this stage, to stabilize their position, tried to work in harmony and in line with the experienced nurses, which was done to win the support of colleagues. In this regard, a participant (nurse No. 5) said:

“... There was no way. I had to somehow coordinate with the rest. Here, if you do not respect the rules and are not aligned with colleagues, many problems will chase you later. They bother you. They do not support you. They may give a bad report about you."

\subsubsection{Showing the Capabilities}

To strengthen their position in the ward, sometimes the newly graduated nurses used the strategy of "presenting their capabilities." To this end, they utilized approaches including performing complex tasks and care measures, observing work principles and regulations, and expressing creative and new ideas. A participant (nurse No. 6) stated:

"I try to follow the correct principles of report writing so that everybody sees that I know the right principles of the work; no one can find a fault in my work and our chief nurse would be satisfied with my work."

In this regard, they took advantage of volunteering for getting things done in presence of officials and respectful behavior with colleagues. One of the head nurses (participant No. 18) stated in this regard:

"Some of the NGNs always volunteer in front of me to do the tasks and show them very active; thus, they do not even sit in my presence, and do the tasks non-stop. In fact, they want to show they know the procedures and routines."

Finally, all of these coping strategies led to "the acceptance of the NGNs in the team," which was the core variable 
Table 1. Demographic Characteristics of Participants $(n=20)$

\begin{tabular}{|c|c|c|c|c|c|c|c|}
\hline \multirow{2}{*}{$\begin{array}{l}\text { Characteristics } \\
\text { NGNs }\end{array}$} & \multirow[t]{2}{*}{ Age } & \multicolumn{2}{|c|}{ Gender } & \multicolumn{2}{|c|}{ Marital Status } & \multirow{2}{*}{$\begin{array}{c}\text { Average Work } \\
\text { Experience } \\
\text { (Month) }\end{array}$} & \multirow{2}{*}{$\begin{array}{c}\text { Age } \\
\text { Range }\end{array}$} \\
\hline & & Female & Male & Single & Married & & \\
\hline Participant 1 & 22 & 1 & - & 1 & - & 6 & \multirow{18}{*}{$22-25$} \\
\hline Participant 2 & 24 & 1 & - & 1 & - & 8 & \\
\hline Participant 3 & 24 & 1 & - & 1 & - & 4 & \\
\hline Participant 4 & 26 & - & 1 & - & 1 & 1 & \\
\hline Participant 5 & 27 & 1 & - & 1 & - & 5 & \\
\hline Participant 6 & 23 & 1 & - & 1 & - & 2 & \\
\hline Participant 7 & 24 & - & 1 & 1 & - & 8 & \\
\hline Participant 8 & 25 & 1 & - & 1 & - & 7 & \\
\hline Participant 9 & 24 & 1 & - & - & 1 & 2 & \\
\hline Participant 10 & 25 & 1 & - & 1 & - & 5 & \\
\hline Participant 11 & 22 & 1 & - & 1 & - & 4 & \\
\hline Participant 12 & 22 & 1 & - & 1 & - & 3 & \\
\hline Participant 13 & 23 & 1 & - & - & - & 4 & \\
\hline Participant 14 & 22 & 1 & - & - & 1 & 2 & \\
\hline Participant 15 & 23 & - & 1 & 1 & - & 1 & \\
\hline Participant 16 & 23 & 1 & - & 1 & - & 10 & \\
\hline Participant 17 & 24 & 1 & - & 1 & - & 11 & \\
\hline Head nurses & & & & & & (Year) & \\
\hline Participant 18 & 48 & 1 & - & - & 1 & 12 & \multirow{3}{*}{$46-50$} \\
\hline Participant 19 & 47 & 1 & - & - & 1 & 16 & \\
\hline Participant 20 & 45 & 1 & - & - & 1 & 27 & \\
\hline
\end{tabular}

Table 2. The Main Categories and Sub-Categories of Coping Strategies Used by Newly Graduated Nurses at the Beginning of Clinical Practice

\begin{tabular}{l|c|c}
\hline \multicolumn{1}{c|}{ Theme } & Main Categories & Sub Categories \\
\hline \multirow{2}{*}{$\begin{array}{l}\text { Coping strategies } \\
\text { used by newly } \\
\text { graduated nurses }\end{array}$} & Positioning & Learning \\
\cline { 2 - 3 } & $\begin{array}{c}\text { Subordination and } \\
\text { obedience }\end{array}$ \\
\cline { 2 - 3 } & $\begin{array}{c}\text { Strengthening the } \\
\text { position }\end{array}$ & $\begin{array}{c}\text { Aligning oneself with } \\
\text { colleagues }\end{array}$ \\
\cline { 2 - 3 } & & $\begin{array}{c}\text { Showing oneself } \\
\text { abilities }\end{array}$ \\
\hline
\end{tabular}

of the study. The newly graduated nurses' coping strategies and their growth trend are shown in Figure 1.

\section{Discussion}

The findings of this study reflected two strategies of "Positioning" and "Position Consolidation." This study showed that the NGNs were trying in the phase of learning to improve their skills. A study in this regard, in agreement with the findings of this study, confirmed the use of different learning mechanisms by NGNs (16). According to the social learning theory, people learn from each other using observational learning, imitation, and modeling. This theory emphasizes the importance of observing and modeling the behaviors, attitudes, and emotional reactions of others (14).

This study showed that the NGNs tried to create a place for themselves in their workplace with compliance and obedience to their supervisors and senior nurses. They were trying to attract their superiors' support in some way and change themselves proportionally and in accordance with the colleagues. These behaviors can be explained by the theory of socialization.

This theory states that in the process of socialization, people learn the required roles and opportunities to participate in community organizations. Socialization refers 


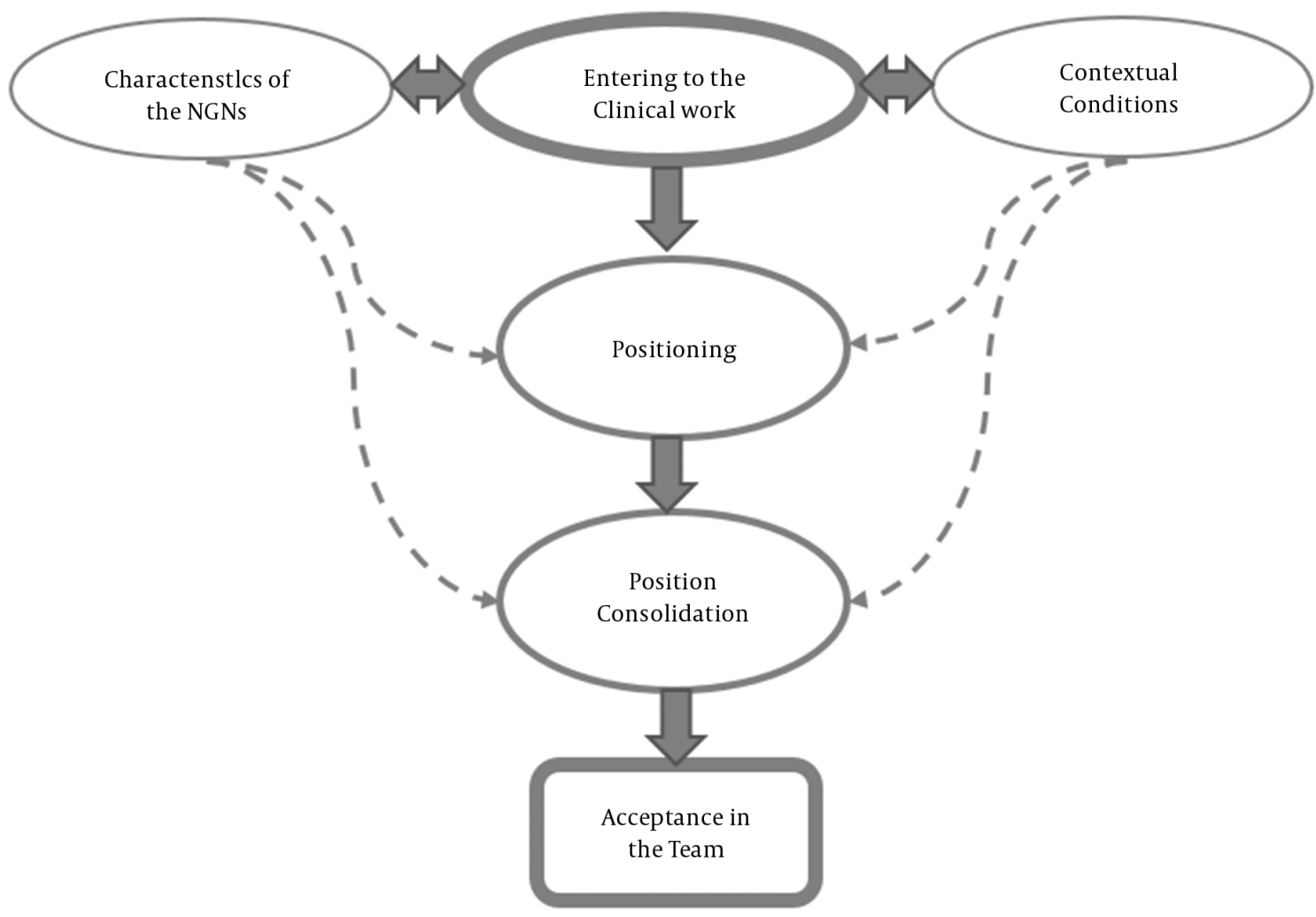

Figure 1. Coping strategies of the NGNs in the first year of clinical practice

to a state that a person adapts himself to the members of a group with the certain culture of that group (17). Professional socialization is generally a developmental process in which an individual acquires professional knowledge, skills, values, beliefs, norms, attitudes, behaviors, and commitment. Interacting with the profession members, an individual gains experiences that are required for his acceptance in that profession $(18,19)$. In the process of socialization, the learning of social roles and norms occurs (20). These findings can also be explained by the theory of Maslow's hierarchy of basic human needs (1954). According to this theory, everyone needs a safe environment and a sense of belonging. A sense of belonging is one of the five basic human needs that occur at the heart of many human behaviors and social phenomena, from infancy to adult$\operatorname{hood}(21)$.

In this study, the NGNs tried to establish a place (safe environment) for themselves by complying and obedience creates a sense of belonging to the nursing team. Therefore, they benefited from these coping strategies to be accepted in the team. The study participants also suggested that they were to strengthen their obtained position. Therefore, they "aligned themselves with colleagues" and "presented their capabilities." One study showed that the beginners try to make them proportionate and consistent with the working environment and the peers. Then, to become a member of the care team, they coordinated and blended themselves with other collogues (22). The findings indicated that the NGNs applied some coping strategies to demonstrate their abilities. Presenting qualifications and demonstrating the clinical abilities were observed in this study. The results of this study can be also explained based on the Benner's theory of skill acquisition (1984) (23). He identified five stages in the development of nursing skills: novice, advanced beginner, competent, proficient, and expert. The NGN is task-oriented and law-abiding and focuses on acquiring skills. Over the time, s/he acquires the features of an advanced beginner. His/her experiences and gradually improves his/her skills by thinking about his/her experiences and shows behaviors involving competence, expertise, and mastery (24). Benner believes that only experiencing can lead to the development of a skilled nurse (22). Although the NGNs do not reach the mastery stage during the first year of clinical practice, almost a model similar to the Benner model representing the qualification was seen in our study. This study showed that nurses had 
acquired a feeling of ability, competence acquisition, and increased self-confidence at the end of the first year of their graduation. They had obtained the ability to take responsibilities and time management (25).

Duchscher (2008) introduced the "transition of the new role of nursing graduates" as "a process of becoming" that consists of three steps of doing, being, and knowing. The entire trip included regular and progressive steps that had an evolutional and developmental state for all the participants. The transition experience for all nursing graduates participating in his study had a tough and yet dynamic nature. The coping strategies emerged in this study are in line with the transition stages cited by him (26). In our study, dynamics, growth, and promotion of new skills in the novice were discovered. In this context, Drury, Francis, and Chapman (2008) identified three steps in the nurse becoming of students in a study using the grounded theory in Australia. These steps included taking the first step, keep moving, and finally, letting them go and moving forward. At any point during an academic trip, these nursing students had different needs. Tailored to the needs, different skills and knowledge were developed in them, which resulted in the professional and individual growth of the nurses (27). This study somewhat confirms our findings

A study (2009) showed that the licensed nurses acquire skills and develop their knowledge during the first 16 to 18 months of their work through their selfrecognition (thinking/learning about themselves), empirical knowledge (the relationship between theory and practice/identifying the gaps), individual knowledge and moral knowledge. They applied their knowledge in practice by identifying the gaps between theoretical knowledge and clinical practice. Their methods of acquiring knowledge indicated an element of professional maturity as a nurse during this period (8). This method described the Carper's knowing methods in nurses (14). The participants of this study had not mentioned the aesthetic knowledge. It is perhaps because the aesthetic knowledge needs deep involvement experiences and the NGNs have not still achieved this level of experience.

This study was conducted qualitatively. Therefore, the limitations of this study can be mentioned as the lack of generalizability of the findings to other populations due to purposive sampling.

\section{Conclusion}

The results showed that many NGNs try to create a social position for their own in the workplace. The findings of this study provide rich information, which can be used as a guide for nursing managers and stakeholders. These findings may result in the development of training programs for newly graduated nurses at the start of working life. Further studies are recommended in this regard.

Ethical consideration

This study was agreed for the protection of human subjects by the institutional review board of Iran University of Medical Sciences (IUMS). The agreement was also granted from the managers of the related hospitals and their nursing administrators. Further permission and written consent were obtained from all the participants.

\section{Acknowledgments}

This study is a part of a Ph.D. thesis and a project approved by IUMS. The authors would like to appreciate the Research Deputy of Iran University of Medical Sciences and all dear participants.

\section{Footnote}

Conflict of Interest: No conflicts of interest are declared by the authors.

\section{References}

1. Steen JE, Gould EW, Raingruber B, Hill J. Effect of student nurse intern position on ease of transition from student nurse to registered nurse. J Nurses Staff Dev. 2011;27(4):181-6. doi: 10.1097/NND.0b013e3181a68acc. [PubMed: 21788745].

2. Hezaveh MS, Rafii F, Seyedfatemi N. The experience of stress among new clinical nurses. Nurs Practic Today. 2015;1(4):199-206.

3. Blomberg K, Isaksson AK, Allvin R, Bisholt B, Ewertsson M, Kullen Engstrom A, et al. Work stress among newly graduated nurses in relation to workplace and clinical group supervision. J Nurs Manag. 2016;24(1):80-7. doi:10.1111/jonm.12274. [PubMed: 25421164].

4. Hezaveh MS, Rafii F, Seyedfatemi N. Novice nurses' experiences of unpreparedness at the beginning of the work. Global J Health Scie. 2014;6(1):215

5. Rafii F, Sajadi Hezaveh M, Naiemeh Seyedfatemi N. Concept Analysis of Transition from Nursing Studentship to Working Life: a Hybrid Model. J Hayat. 2014;20(1):59-73.

6. Mooney M. Facing registration: the expectations and the unexpected. Nurse Educ Today. 2007;27(8):840-7. doi: 10.1016/j.nedt.2006.11.003. [PubMed: 17234304].

7. Rafii F, Sajadi Hezaveh M, Seyedfatemi N, Rezaei M. Factors Affecting the Process of Role Transition from Nursing Student to Clinical Nurse: a Grounded Theory Study. Iran J Nurs. 2015;27(92):44-56.

8. Newton JM, McKenna L. The transitional journey through the graduate year: a focus group study. Int J Nurs Stud. 2007;44(7):1231-7. doi: 10.1016/j.ijnurstu.2006.05.017. [PubMed:16867302].

9. Scott ES, Engelke MK, Swanson M. New graduate nurse transitioning: necessary or nice? Appl Nurs Res. 2008;21(2):75-83. doi: 10.1016/j.apnr.2006.12.002. [PubMed: 18457746].

10. Rafii F, Sajadi Hezaveh M, Seyedfatemi N, Reaei M. Nurse managers' strategies for facilitating transition process newly nurses to clinical nurses. Quarterly Journal of Nursing Management. 2015;4(2).

11. Polit DF, Beck CT. Essentials of nursing research: Appraising evidence for nursing practice. Lippincott Williams Wilkins; 2018. 
12. Corbin J, Strauss A. Basics of qualitative research: Techniques and procedures for developing grounded theory. 2008.

13. Chen HY, Boore JR. Using a synthesised technique for grounded theory in nursing research. J Clin Nurs. 2009;18(16):2251-60. doi: 10.1111/j.1365-2702.2008.02684.x. [PubMed: 19374696].

14. Holloway I, Galvin K. Qualitative research in nursing and healthcare. John Wiley Sons; 2016.

15. Polit D, Beck C. Nursing research: generating and assessing evidence for nursing research. Philadelphia: Lippincott Williams Wilkins; 2008.

16. Malouf N, West S. Fitting in: a pervasive new graduate nurse need. Nurse Educ Today. 2011;31(5):488-93. doi: 10.1016/j.nedt.2010.10.002. [PubMed: 21036429].

17. Bisholt BK. The professional socialization of recently graduated nurses-experiences of an introduction program. Nurse Educ Today. 2012;32(3):278-82. doi: 10.1016/j.nedt.2011.04.001. [PubMed: 21546139].

18. Kramer M, Brewer BB, Maguire P. Impact of healthy work environments on new graduate nurses' environmental reality shock. West J Nurs Res. 2013;35(3):348-83. doi: 10.1177/0193945911403939. [PubMed: 21498813].

19. Read E, Laschinger HKS. Transition experiences, intrapersonal resources, and job retention of new graduate nurses from accelerated and traditional nursing programs: A cross-sectional comparative study. Nurse Educ Today. 2017;59:53-8. doi: 10.1016/j.nedt.2017.08.014. [PubMed: 28941879].

20. Wolff AC, Pesut B, Regan S. New graduate nurse practice readiness: perspectives on the context shaping our understand- ing and expectations. Nurse Educ Today. 2010;30(2):187-91. doi: 10.1016/j.nedt.2009.07.011. [PubMed:19699561].

21. Rush KL, Adamack M, Gordon J, Lilly M, Janke R. Best practices of formal new graduate nurse transition programs: an integrative review. Int J Nurs Stud. 2013;50(3):345-56. doi: 10.1016/j.ijnurstu.2012.06.009. [PubMed: 22795800].

22. Bott G, Mohide EA, Lawlor Y. A clinical teaching technique for nurse preceptors: the five minute preceptor.J Prof Nurs. 2011;27(1):35-42. doi: 10.1016/j.profnurs.2010.09.009. [PubMed: 21272834].

23. Meleis AI. Theoretical nursing: Development and progress. Lippincott Williams Wilkins; 2011.

24. Dyess SM, Sherman RO. The first year of practice: new graduate nurses' transition and learning needs. J Contin Educ Nurs. 2009;40(9):403-10. doi: 10.3928/00220124-20090824-03. [PubMed: 19754027].

25. Andersson PL, Edberg AK. The transition from rookie to genuine nurse: narratives from Swedish nurses 1 year after graduation. J Contin Educ Nurs. 2010;41(4):186-92. doi: 10.3928/00220124-20100326-05. [PubMed: 20411891].

26. Duchscher JB. A process of becoming: the stages of new nursing graduate professional role transition. J Contin Educ Nurs. 2008;39(10):44150. quiz 451-2, 480. [PubMed: 18990890].

27. Drury V, Francis K, Chapman Y . Mature learners becoming registered nurses: a grounded theory model. Australian J Advanced Nurs. 2008;26(2):39. 